\title{
Nota bene
}

En raison du contexte sanitaire et des difficultés d'acheminement des ouvrages, la composition d'un ensemble de comptes rendus n'a pas été possible. Nous reprendrons cette pratique dès le prochain numéro.

\section{Erratum}

AHSS, 74-2, 10.1017/ahss.2020.12, publié par Cambridge University Press, 23 juin 2020

Dans le compte rendu d'origine (Bessin 2019), le nom d'un des directeurs d'ouvrage était malencontreusement orthographié "Mark Tamm » au lieu de Marek Tamm. La même erreur se retrouvait dans la deuxième entrée de la liste des comptes rendus à la page 502 de ce numéro 74-2. Dans cette entrée, la première page de la pagination était également erronée («p. 431-434 » au lieu de «p. 432-434»).

Les versions originales PDF et HTML en ligne de ce compte rendu ont été corrigées, intégrant ces modifications.

Marek Tamm et Laurent Olivier (dir.), Rethinking Historical Time: New Approaches to Presentism, Londres, Bloomsbury Academic, 2019 (Marc Bessin). Annales HSS, 74-2, p. 432-434, DOI:10.1017/ ahss.2020.12.

La version originale de ce compte rendu a été publiée avec une erreur. Un erratum a été publié et l'erreur rectifiée dans les versions PDF et HTML en ligne. 